\title{
O PLANEJAMENTO URBANO EM SÃO LUÍS PELA LEGISLAÇ̃̃o DE ZONEAMENTO, PARCELAMENTO, USO E OCUPAÇÃO DO SOLO: LIMITES AO DIREITO À CIDADE PELO PROCESSO DE PRODUÇÃO DO ESPAÇO.
}

\author{
Luiz Eduardo Neves dos Santos \\ Universidade Federal do Maranhão, Campus Pinheiro, MA, Brasil. \\ Pós-Graduação em Geografia, Universidade Federal do Ceará, Fortaleza, CE, Brasil \\ dugeografo@hotmail.com; luiz.neves@ufma.br \\ Maria Clélia Lustosa Costa \\ Departamento de Geografia, Universidade Federal do Ceará, Fortaleza, CE, Brasil \\ Programa de Pós-Graduação em Geografia, Universidade Federal do Ceará, Fortaleza, CE, Brasil \\ clelialustosa@gmail.com
}

\begin{abstract}
RESUMO
O presente trabalho de pesquisa apresenta uma análise sobre o planejamento urbano no município de São Luís, capital do Estado do Maranhão, pela legislação de zoneamento, parcelamento, uso e ocupação do solo e de como ela influencia nas formas de produção do espaço, interferindo nos modos de apropriação da cidade por parte da maioria de seus habitantes, que não gozam de qualidade de vida, nem usufruem da infraestrutura adequada, impedindo a concretização do direito à cidade. A discussão gira em torno da influência da legislação de 1975 momento em que há uma inflexão no município de São Luís, representada pela rápida expansão do seu espaço urbano via investimentos do governo federal, mas principalmente da Lei de Zoneamento de 1992, ainda vigente, que traz em seu texto a novidade da instauração das chamadas Zonas de Interesse Social (ZIS), importante instrumento para populações vulneráveis, mas que na prática ainda não atingiu por completo seus objetivos, representado pela garantia da regularização fundiária aliada à consolidação da infraestrutura e acesso aos equipamentos urbanos.
\end{abstract}

Palavras-chave: Planejamento urbano. Lei de Zoneamento. Direito à Cidade. São Luís.

\section{THE URBAN PLANNING IN SÃO LUÍS BY THE LEGISLATION OF ZONEING, PARCELMENT, USE AND OCCUPATION OF THE SOIL: LIMITS TO THE RIGHT TO THE CITY BY THE PROCESS OF PRODUCTION OF THE SPACE}

\begin{abstract}
This research presents an analysis of urban planning in the municipality of São Luis, capital of the State of Maranhão, by the legislation of zoning, subdivision, use and occupation of the land and how it influences the forms of production of the space, interfering in the modes of appropriation of the city by the majority of its inhabitants, who do not enjoy quality of life, nor enjoy the proper infrastructure, preventing the realization of the right to the city. The discussion revolves around the influence of the legislation of 1975, when there is an inflection in the municipality of São Luís, represented by the rapid expansion of its urban space through federal government investments, but mainly of the Zoning Law of 1992, still in force, which brings in its text the novelty of the introduction of the so-called Social Interest Zones, an important instrument for vulnerable populations, but which in practice has not yet fully achieved its objectives, which is a guarantee of land regularization combined with the consolidation of infrastructure and access to urban equipment
\end{abstract}

Keywords: Urban planning. Zoning law. Right to the city. São Luís.

\section{INTRODUÇÃO}

O planejamento urbano é fundamental na condução e administração de qualquer cidade, pequena, média ou grande, seus diversos instrumentos servem ao menos na teoria, como organizadores e reguladores da produção do espaço urbano. Os diferentes conjuntos de leis urbanísticas, com seu aparato técnico de regulação e controle do solo, têm o poder de interferir no futuro de uma cidade a ponto de definir os direcionamentos de apropriação e dominação dos territórios. 
Vivemos progressivamente em áreas urbanas divididas e tendentes ao conflito (HARVEY, 2012). A cidade em países como o Brasil, neste sentido, se apresenta com sérios problemas de desigualdade e o poder público, via leis de uso e controle do solo urbano, são em alguma medida, responsáveis por reforçar essa problemática.

Pelo exposto, o presente artigo tem como objetivo - ainda que de forma incompleta - analisar o papel da legislação urbanística do zoneamento em São Luís, capital do Estado do Maranhão, enquanto instrumento de planejamento urbano por excelência, imposto pela ação estatal municipal e as metamorfoses no processo de produção do espaço e no tocante o direito à cidade.

Desta forma, o trabalho também possui como meta a construção de uma breve abordagem histórica do contexto nacional, regional e local sobre o planejamento urbano e suas leis urbanísticas, contextualizando-as nas suas relações, material e ideológica, com o espaço urbano de São Luís. Visa ainda problematizar conceitos e categorias teóricas como planejamento urbano, direito à cidade, produção do espaço, Plano Diretor e Leis de Zoneamento.

Buscou-se ainda demonstrar as interações existentes entre o capital imobiliário e a política municipal urbana no tocante aos critérios de escolha e delimitação das zonas onde há intensa especulação imobiliária, verticalização, e, sobretudo, a criação das Zonas de Interesse Social (ZIS).

Levando em consideração a orientação metodológica, se empregou técnicas que valorizam a coleta de informações necessárias ao entendimento do objetivo discriminado no trabalho. Destaca-se a revisão de literatura, incluindo pesquisas em livros e artigos, dissertações, análise e interpretação da legislação urbanística, produção de material iconográfico e a elaboração de mapas, gráficos e tabelas.

\section{PRODUÇÃO DO ESPAÇO, PLANEJAMENTO URBANO E DIREITO À CIDADE: ALGUMAS CONSIDERAÇÕES}

A concepção de espaço é aqui compreendida como uma instância social de produção e reprodução da vida dos seres humanos, dimensão concreta da sociedade, produto histórico da luta de classes. O espaço só poderá ser inteligível através da sociedade, da mesma forma, a sociedade só se torna concreta pelo espaço (SANTOS, 2005, p. 22).

A expressão "produção do espaço" foi desenvolvida por Henri Lefebvre em 1975 na obra "A produção do espaço" (La production de l'espace). Tal categoria proposta pelo filósofo faz referência aos processos de atuação das forças produtivas do capital no espaço, assim como suas interferências na produção das relações sociais e ideológicas entre grupos.

Lefebvre (1991, p. 37) indica a relevância do sentido do termo 'produção', que adquire segundo ele um sentido amplo e vigoroso na esfera do cotidiano, não se reduzindo apenas a fabricação material de produtos, mas também a criação de obras, que incluem tempo e espaço sociais, relações sociais, ideologias, cultura, valores e costumes. Milton Santos, apesar de possuir uma teoria do espaço distinta de Lefebvre, admite que o "ato de produzir é igualmente o ato de produzir espaço" (SANTOS, 2012, p. 202). Ao aprofundar suas análises sobre o espaço, o geógrafo baiano, forjou o termo "Formação Sócio-Espacial", influenciado pelo conceito de Formação Econômica e Social de Marx.

Para Villaça (2010, p. 173), "o planejamento urbano é a ação do Estado sobre a organização do espaço intraurbano". Essa ação - no sentido do tempo presente, ligado à gestão urbana - deve ser entendida como um conjunto, que tem a ver com alcance de resultados futuros. É preciso ressaltar que a ação do Estado em relação ao planejamento nas cidades se faz também no plano da dominação ideológica (BURNETT, 2011), ou seja, a partir da produção de discursos sobre o espaço urbano, contribuindo para "ocultar a cidade real e para a formação de um mercado imobiliário restrito e especulativo" (MARICATO, 2000, p. 124). O aparato regulatório, como a legislação urbanística, Plano Diretor e seus instrumentos dão sustentação ao Estado, tanto no plano ideológico como no concreto.

A concepção de "direito à cidade" foi desenvolvida primeiramente pelo pensador francês Henri Lefebvre nos anos 1960, e diz respeito ao direito de se poder vivenciar o urbano com os benefícios inerentes a tal espaço. Para Lefebvre (2001, p. 108), o direito à cidade tem a ver com um "novo humanismo que devemos tender e pelo qual devemos nos esforçar, isto na direção de uma nova práxis e de um outro homem, o homem da sociedade urbana". O direito à cidade não se reduz a mero acesso a recursos urbanos, 
é um direito de mudar e reinventar a cidade mais de acordo com os nossos mais profundos desejos. Além disso, é um direito mais coletivo que individual, uma vez que reinventar a cidade depende inevitavelmente do exercício de um poder coletivo sobre o processo de urbanização. A liberdade de fazer e refazer a nós mesmos e as nossas cidades [...] é um dos nossos direitos humanos mais preciosos, ainda que um dos mais menosprezados (HARVEY, 2014, p. 28).

David Harvey atualiza o conceito de Lefebvre ao afirmar que "vivemos num mundo onde os direitos de propriedade privada e a taxa de lucro se sobrepõem a todas as outras noções de direito" (HARVEY, 2012, p. 73). O geógrafo inglês vê um grande problema no que tange à grande absorção de excedentes de capital que se direcionam aos espaços construídos, propiciando distorções graves entre classes nos espaços das cidades, a exemplo da "acumulação por espoliação" (HARVEY, 2013), termo que se refere à aquisição pelo mercado, de terrenos na cidade que estão na posse de pessoas mais pobres e que não possuem o título de propriedade em virtude da valorização dessas terras.

É preciso repensar a concepção de direito à cidade para a realidade brasileira, uma sociedade que se urbanizou precariamente mediante migração da força de trabalho das massas rurais expropriadas na segunda metade do século $X X$, ocasionado "uma metropolização precoce e explosiva [...] ocasionando a formação de uma ordem urbana desigual e combinada (RIBEIRO, 2016, p. 130). Tais massas encontram no urbano, obstáculos a sua reprodução, já que este espaço é uma mercadoria valiosa, controlada pela ação conjunta entre o Estado e as grandes corporações privadas nacionais e estrangeiras, que tem no capital financeiro o seu poder.

\section{OCUPAÇÃO E URBANIZAÇÃO EM SÃO LUÍS: UMA SÍNTESE}

Desde o século XVI, segundo historiadores como Amaral (2003) e Lacroix (2008), exploradores europeus, dentre eles portugueses, espanhóis e franceses já haviam pisado no solo da llha de Upaon Açu, ou Grande llha, denominada assim por índios tupinambás que ali viviam e que hoje corresponde à Ilha do Maranhão, da qual São Luís é seu principal município. Os lusos, "donos do lugar", tiveram muita dificuldade em estabelecer uma ocupação efetiva na região, tanto pela navegação por um litoral recortado, como pelo trajeto via continente. Segundo Meireles (2002, p. 26-27), era "impraticável seu caminho por terra, devido não somente às barreiras naturais, como travessias de rios caudalosos, mata fechada, relevo acidentado, mas também pela hostilidade dos nativos indígenas". Ao contrário, navegadores franceses, detinham bons conhecimentos de navegabilidade naquelas águas e mantinham boas relações com os nativos (LACROIX, 2008).

São Luís do Maranhão, portanto, nasceu durante o período Colonial ainda no século XVII. Sua ocupação constituiu-se como estratégia da Coroa Portuguesa em impedir que povos inimigos se apropriassem do território. Durante a segunda metade do século XVIII atingiu o seu apogeu econômico com a exploração do tráfico negreiro e pela produção e exportação de seu principal produto à época, o algodão (MEIRELES, 2002).

O algodão, juntamente com o tráfico de escravos, propiciou uma acumulação de riqueza representada pela arquitetura do seu centro antigo, com a maior quantidade de casarões portugueses no mundo fora de Portugal (LOPES, 2008). Após o declínio da atividade algodoeira e da crise do tráfico negreiro, São Luís perde importância econômica em escala nacional no século XIX.

O século XIX foi marcado por um controle maior do espaço urbano, não só em São Luís, como nos mais diversos núcleos urbanos brasileiros, através dos chamados códigos de posturas municipais, que já eram uma realidade na colônia no século XVIII, mas se detalharam e se diversificaram no oitocentos.

Segundo Gebara (1986), as posturas municipais, no século XIX, funcionavam como um mecanismo de controle social, referindo-se a um grande número de questões pertinentes à administração pública municipal, relacionadas a aspectos da vida diária como os costumes e problemas enfrentados pelos atores sociais que constituíam a urbe. Foram forjados com o objetivo de impor e manter uma ordem pública, visando dar mais força político-administrativa ao município, sem que sua instituição fosse quebrantada diante das transformações que aconteceram na época.

Os Códigos de Posturas foram instrumentos jurídico-administrativos utilizados para organizar o espaço urbano, é um "mecanismo que visa integrar os atores sociais a um projeto de civilização, cuja consolidação passa pela disseminação da idéia da necessidade de um espaço público ordenado" (CARVALHO, 2005, p. 17). Em São Luís, os códigos de postura refletiam as ideologias das classes

$\begin{array}{lllll}\text { Caminhos de Geografia } & \text { Uberlândia-MG } & \text { v. 21, n. } 74 & \text { Abr/2020 } & \text { p. 36-50 Página } 38\end{array}$


dominantes desde 1842, quando da publicação do primeiro código na cidade. Tais ideologias, arregimentadas pelo discurso de uma cidade ideal, se direcionavam no embelezamento do núcleo urbano, na permissão dos tipos de construções e atividades permitidas e proibidas na cidade, na segurança, nos comportamentos, na salubridade e no higienismo.

Em 1871 começou a operar em São Luís a Companhia Ferro Carril, que fazia o transporte urbano com bondes de tração animal. Nos anos seguintes, houve também a instalação de uma estrada de ferro atingindo áreas suburbanas (LOPES, 2008). O aumento da população, embora em ritmo lento, e a diversificação da economia local aliado às dificuldades na comercialização internacional do algodão, além da libertação dos escravos, "foram fatos que contribuíram para uma 'explosão' industrial em São Luís" (RIBEIRO JUNIOR, 2001, p. 102). A proliferação das fábricas no território da cidade - 24 estabelecimentos fabris - facilitou um fluxo maior pessoas a lugares mais distantes, a exemplo da fábrica no Cutim-Anil (MEIRELES, 2015).

O avanço nos transportes aliado a grande quantidade de fábricas em São Luís, contribuiu bastante para uma certa expansão da cidade, representado pelo aparecimento de alguns núcleos, que mais tarde viriam a se transformar em bairros que surgiram ao longo do divisor de águas dos rios Anil e Bacanga (BURNETT, 2012). As fábricas aqui instaladas na segunda metade do século XIX representaram uma desconcentração de serviços e da malha viária, embora isso não significasse um incremento substancial do ponto de vista demográfico.

O início do século XX é marcado por um período de estagnação econômica, somente na década de 1920 é que se observa um marco na política dos serviços públicos, influenciando numa maior modificação da estrutura urbana de São Luís. "A Companhia norte-americana Ulen Management foi implantada na cidade, passando a concentrar a produção e o comando dos serviços de água, esgoto, luz e tração elétrica" (MEIRELES, 2002, p, 217). Porém esta Companhia não cumpriu seu papel, não atendendo satisfatoriamente os serviços propostos no contrato inicial, trazendo prejuízos para a cidade que ainda carecia de serviços básicos de infraestrutura.

Saboya Ribeiro, engenheiro e urbanista cearense, é nomeado prefeito em 1936, sob a gestão do Interventor Federal no Maranhão, Paulo Martins de Souza Ramos, tendo como desafio a remodelação abrangente e sistemática do espaço urbano de São Luís que deveria interferir também nos hábitos da população. Para Lopes (2013, p. 171), a reforma urbana de Saboya Ribeiro se baseava na "reorganização da gestão, legitimação social das propostas, visão totalizante da cidade, intervenção em edifícios públicos, circulação viária, ações higienistas e estética urbana". Paulo Ramos promoveria o que se chamou na época de 'a reconstrução do Maranhão', inaugurando um período "dos mais profícuos e progressistas que já desfrutou o Maranhão" (MEIRELES, 2002, p. 336). Essa concepção de Meireles, um tanto ufanista, é reforçada pela mentalidade da época, presente entre intelectuais, lideranças políticas locais e nos quadros políticos nacionais, da ideia de que o perfil técnico de um líder - no caso Saboya Ribeiro - seria capaz de levar adiante o projeto modernizador preconizado por Getúlio Vargas.

Em 1937 Paulo Ramos inicia um programa de reforma e construção de estradas no Estado e em São Luís. Sua emergente malha urbana se diferenciaria daquela que atendia o padrão do século XIX (LOPES, 2008). De modo que a cidade cresce a partir chamado Caminho Grande, que se torna então o principal sistema viário da ilha do Maranhão. Esta estrada partia do Centro da cidade em direção ao bairro do Anil e a partir daí se direcionava a São José de Ribamar (SANTOS, 2010).

Pedro Neiva de Santana assume a prefeitura em novembro de 1937 e dá continuidade ao trabalho do antecessor, Saboya Ribeiro. No fim de 1938, através do Decreto oㅡ 330 de 3 de junho, Pedro Neiva aprova um Zoneamento para São Luís, estabelecendo 4 Zonas (Comercial, Industrial, Residencial e Agrícola) e um Centro Administrativo, que priorizou a ordem econômica, sanitária e estética e abrangia apenas a área central da cidade (LOPES, 2013).

A expansão urbana de São Luís tem como uma de suas maiores expressões a ocupação do eixo Centro-Anil. Segundo Gomes (1988) nas décadas de 1920, 1930 e 1940 São Luís possuía um lento crescimento da área urbana, permitindo com que a cidade atraísse recursos direcionados à urbanização, como algumas tímidas melhorias em saúde, educação, transporte, energia e saneamento. A partir das décadas de 1940 a cidade de São Luís "expande-se numa faixa de aproximadamente 13 quilômetros de extensão" (GOMES, 1988, p. 21-22), sendo que a topografia pouco favorável, situada no divisor de águas dos dois principais rios da ilha, fez com que este crescimento se direcionasse aos mangues. 
Ribeiro Júnior (2001, p. 89) afirmou que "entre os anos de 1930 a 1970, a cidade de São Luís recebeu milhares de migrantes vindos do campo, fazendo com que as áreas da Avenida Getúlio Vargas fossem ocupadas". Com a chegada dos migrantes surgem as localidades do Areal, hoje bairro do Monte Castelo, Matadouro, atual bairro da Liberdade, Cavaco, hoje bairro de Fátima, João Paulo, Filipinho, Anil, entre outros (SANTOS, 2009a). A partir da política econômica do governo militar, com a construção da ponte José Sarney e da Barragem sobre o rio Bacanga, a cidade se expande para outros espaços, possibilitando o surgimento de uma série de conjuntos habitacionais.

\section{O ESTADO AUTORITÁRIO COMO PONTO DE INFLEXÃO DA URBANIZAÇÃO E DO PLANEJAMENTO URBANO LUDOVICENSE}

Após o golpe militar em 1964, o Brasil, e em particular o Maranhão, foram tomados por um momento de euforia no campo econômico, sobretudo com o que foi estabelecido pelos dois Planos Nacionais de Desenvolvimento, que previam, dentre outras metas, o crescimento econômico através do PIB, o aumento da renda per capita, o controle da inflação, a diversificação industrial e o desenvolvimento urbano, isso como forma de combater um período de intensa estagnação (ALMADA, 2017).

Ainda na década de 1960, São Luís acompanha o planejamento nacional via dinamização de sua economia que buscava novos investimentos, a exemplo da construção de um novo porto que pudesse escoar as riquezas da serra dos Carajás, articulando-a ao capital estrangeiro e ao mercado global. Nos anos 1960 foi registrada uma taxa de incremento populacional que somava quase o dobro da registrada na década anterior (MARANHÃO, 1976). Paralelo a este quadro, era registrado também o crescimento da habitação informal, instigada pela ausência direta do Estado na questão e pelo achatamento salarial, o que, conforme assinala Ribeiro Junior (2001), levou pelo menos $16 \%$ da população da capital maranhense a recorrer às moradias subnormais.

Até 1970 a população ainda crescia de forma moderada, embora com um acréscimo ainda não visto na história urbana da cidade. No período 1950-1970 foram incorporadas 145.701 pessoas na cidade, que em termos cumulativos representavam 265.486 habitantes (SANTOS, 2009b). De Acordo com Ribeiro Junior (2001), a construção, no início de 1968, da ponte de concreto sobre o rio Anil ligando os bairros do Caratatiua e Ivar Saldanha (onde mais tarde se levantaria os conjuntos habitacionais do Maranhão Novo, 1970; IPASE, 1971 e COHAMA, 1975), que representou um avanço da cidade para margem direita do rio Anil. De acordo com Ferreira (2002, p. 28), entre 1951-1970, o crescimento horizontal de São Luís "foi de $9,87 \mathrm{~km}^{2}$ ou $137,66 \%$ em relação ao período de $1612-1950$, sendo ainda lento e linear".

Os anos 1970 ficaram marcados ainda pela promulgação de uma importante Lei, o Plano Diretor de 1975 e seu respectivo Código de Zoneamento na gestão do então engenheiro civil e prefeito Haroldo Tavares. O Plano foi um marco devido sua abrangência e diversificação, foi o primeiro a atingir a totalidade do município. Foi contratado o escritório Wit-Olaf Prochnik - Arquitetura e Planejamento S.C.L. com uma equipe multidisciplinar para realizar os estudos (MARANHÃO, 1977).

A partir da consulta do texto da legislação, infere-se que tal marco legal se fazia necessário por dois motivos principais: 1. preparar o território do município para receber os investimentos do Programa Grande Carajás e do Porto do Itaqui; 2. ordenar e controlar a expansão urbana pelo uso adequado da terra com criação de um sistema viário maior em consequência do incremento de muitos conjuntos habitacionais via recursos do Sistema Financeiro de Habitação, Banco Nacional de Habitação e o Banco do Nordeste. É bom lembrar que esses dois motivos estavam relacionados diretamente com os programas desenvolvimentistas do Estado brasileiro, custeado em grande parte pelos investimentos do capital estrangeiro.

O Código de Zoneamento do Plano Diretor de 1975 estabeleceu 6 Zonas a saber: a Zona Central, os Centros de Bairro, as Zonas Industriais, as Zonas Residenciais, as Zonas Especiais e a Zona Rural (MARANHÃO, 1977). Com exceção das Zonas Rural e Central, todas as outras apresentaram subdivisões.

Temas relevantes foram colocados no Código, a exemplo da questão ambiental, que se tornou uma preocupação mundial com a Conferência de Estocolmo realizada dois anos antes e promovida pela ONU. Das oito Zonas Especiais, cinco estavam relacionadas ao meio ambiente. Destacamos a Zonas de interesse paisagístico do litoral norte (ZE-1), a Zona de Proteção das Bacias Hidrográficas (ZE-5) e a Zona de proteção ao lago do Bacanga (ZE-8). Nas Zonas Especiais também foi dada importância

$\begin{array}{lllll}\text { Caminhos de Geografia } \quad \text { Uberlândia-MG } & \text { v. 21, n. } 74 \quad \text { Abr/2020 } & \text { p. 36-50 Página } 40\end{array}$


ao patrimônio histórico arquitetônico pelos casarões coloniais, a partir da Zona de interesse histórico para fins residenciais (ZE-3) e Zona interesse histórico para fins comerciais (ZE-4).

As Zonas Residenciais atendiam áreas da cidade com os loteamentos em que os conjuntos habitacionais estavam ocupando ou iriam ocupar. As Zonas Industriais foram escolhidas à sudoeste do município, se consolidando nos anos 1980 com o protagonismo da Companhia Vale do Rio Doce e da ALUMAR, consórcio formado pela Alcoa e BHP Billinton. A inserção desses empreendimentos possibilitou ainda a construção de portos (Itaqui e Ponta da Madeira) que recebem os fluxos da extração minérios do Pará e da confecção do Alumínio em São Luís.

Em 1981, através da Lei no 2527, é instituído uma nova Lei de zoneamento, parcelamento, uso e ocupação do solo, muito parecida com a legislação de 1975, mas com algumas novidades nos usos e índices. Foram acrescentadas três zonas, A Zonas de Reservas, subdividida em Zona de Reserva Florestal (ZRF) e a Zona de Proteção Ambiental, além de uma Zona de Expansão Urbana (ZEU) (SÃO LUÍS, 1981).

As duas leis citadas, sobretudo o Plano Diretor de 1975 e seu Código de Zoneamento, foram de extrema importância, já que constituíram objeto de pesquisas e diagnósticos socioeconômicos, históricos e ambientais, abrangendo a totalidade do município, mas não foram capazes de conter o avanço urbano desenfreado - só entre 1960 e 1991 a população de São Luís mais que quadruplicou, passando de 158.292 habitantes para 695.199 habitantes (IBGE, 1960; 1991). Tais legislações não previram os efeitos ocasionados pela promulgação da Lei de Terras do Governo Sarney no fim dos anos 1960, que determinava a venda de terras devolutas do interior do Estado a grupos de fora do Estado sem licitação e a preços módicos (ASSELIN, 2009), o que acarretou a expulsão do pequeno lavrador do campo, que se direcionou principalmente à São Luís e ao Estado do Pará.

O tópico seguinte analisará os efeitos da legislação urbanística de 1992, principalmente a lei de zoneamento, parcelamento, uso e ocupação do solo em São Luís, que trouxe como principal novidade a instauração das Zonas de Interesse Social.

\section{O PLANO DIRETOR E O ZONEAMENTO DE 1992: EFEITOS PARA O ESPAÇO URBANO DE SÃO LUÍS}

A luta pela reforma urbana no Brasil inicia na década de 1960, tempo que setores progressistas da sociedade reivindicavam por reformas estruturais na questão fundiária das cidades, que começavam a sofrer os efeitos da rápida urbanização. A principal bandeira levantada foi a realização da Reforma Agrária no campo, parte já do plano das "Reformas de Base" no governo João Goulart. A proposta de uma reforma urbana nas cidades brasileiras foi primeiramente formulada em 1963, em congresso promovido pelo Instituto dos Arquitetos do Brasil (CARVALHO, 2016). Mas o golpe militar de 1964 inviabilizou o florescimento da mobilização em torno da reforma urbana.

No fim dos anos $1970 \mathrm{com}$ uma flexibilidade gradual do regime militar, houve uma reorganização em torno da reforma urbana novamente, e foi em 1987, na constituinte, que houve uma grande vitória por parte dos movimentos socais em torno do tema. Uma Emenda Popular pela Reforma Urbana é proposta. Tal emenda conta com o acúmulo teórico da questão urbana e o avanço político dos movimentos populares, recebe 200.000 mil assinaturas e contribui para a incorporação dos capítulos 182 e 183 sobre a política urbana no texto da Constituição (GRAZIA, 2012). É neste contexto que, nos anos 1990, dezenas de cidades grandes e médias no Brasil elaboram, de forma mais detalhada, seus planos diretores e respectivos zoneamentos, como Fortaleza (Leis no 7.061/1992 e 7.987/1996), Recife (Leis no 15.547/1991 e 16.176/1996), Belo Horizonte (Leis no 7.165/1996 e 7.166/1996), Rio de Janeiro (Lei no 16/1992) e São Luís (Leis no 3.252/1992 e 3.253/1992), só para ficar em alguns exemplos.

O zoneamento - uma modalidade de planejamento urbano - é definido como um instrumento bastante utilizado nos planos diretores, através do qual a cidade é dividida em zonas sobre as quais recaem diretrizes distintas para o uso e a ocupação do solo, principalmente os índices urbanísticos. Para Ribeiro e Cardoso (2012, p. 114), o "zoneamento deve servir, então, para o controle do uso do solo, tendo em vista a preocupação de proteger certos padrões de qualidade de vida e, ao mesmo tempo, de gestão democrática da cidade". Na prática, em diversas cidades, o zoneamento não cumpre o que os autores afirmam, por uma série de questões, a exemplo da determinação dos tipos 
de uso em função de usos já consolidados, a lei apenas os reconhece, mesmo que a realidade seja perversa e desigual.

O zoneamento é uma lei complexa, por conter grande quantidade de índices com números em tabelas, a população, em sua maioria, desconhece o que essa legislação estabelece, embora ela afete a vida de milhões de pessoas nas cidades brasileiras. Por conta disso, essa legislação tende a favorecer interesses do empresariado do ramo imobiliário e da construção civil em São Luís, acentuando desigualdades socioespaciais (MARICATO, 2001).

Em dezembro de 1992, na gestão do prefeito Jackson Lago, é aprovado o Plano Diretor (Lei no 3.252/1992) e sua lei complementar, o zoneamento (Lei oㅜ 3.253/1992). Tais legislações foram elaboradas por um conjunto de especialistas, principalmente arquitetos e urbanistas, sem nenhum diálogo com a sociedade civil, algo comum no Brasil à época. Este grupo de especialistas compôs a equipe do Instituto de Pesquisa e Planejamento do Município (IPLAM), órgão criado pela mesma lei do Plano Diretor.

O zoneamento de 1992 ainda está vigente, passados 26 anos houve modificações e acréscimos na lei. Originalmente ela conta com 26 zonas em 11 tipologias distintas (1. Zonas Residenciais, 2. Zonas Turísticas, 3. Zona Administrativa, 4. Zona Central, 5. Zona de Preservação Histórica, 6. Zonas de Proteção Ambiental, 7. Zona de Segurança do Aeroporto, 8. Zona de Reserva Florestal, 9. Zonas de Interesse Social, 10. Zonas Industriais e Zona Rural) e 12 corredores viários.

\section{O PAPEL DAS ZONAS DE INTERESSE SOCIAL NO ZONEAMENTO DE 1992 E SEUS IMPACTOS}

O Zoneamento de 1992 entra em vigor numa época de crise econômica e alta inflação no Brasil, os investimentos em habitação eram baixos, o que ocasionou "intervenções seletivas no espaço urbano da cidade, com o critério preponderante de assegurar, aos investimentos privados, retorno rápido e sem risco" (BURNETT, 2012, p. 108). Assim, tal legislação permitiu no início, uma mudança no padrão construtivo de algumas partes da cidade, sobretudo no que tange ao processo de verticalização, determinando um número maior no gabarito máximo para algumas zonas residenciais e nas zonas turísticas, beneficiadas com grandes investimentos.

Em 1992 é aprovada também a lei no 3.255, que delimita pela primeira vez na história do município as Zonas de Interesse Social, a ZIS 1 (destacadas no mapa da figura 1 em vermelho) que buscou garantir a permanência de populações carentes em áreas consolidadas na zona urbana e a ZIS 2 (delimitou-se apenas uma área na zona urbana que posteriormente se transformou em ZIS 1). Depois da publicação do Plano Diretor em 2006, houve nos anos subsequentes a implantação de mais 7 Zonas de Interesse Social (a ZIS 2, hachuradas em amarelo no mapa da figura 1), sem que houvesse uma discussão mais ampla com a sociedade e com os moradores das áreas, que se localizariam, principalmente, em lugares pouco urbanizados no município, sem o mínimo de infraestrutura e com uma rede de transporte público precária.

As ZIS, mais popularmente conhecida como ZEIS (Zonas Especiais de Interesse Social) no Brasil, são áreas que se caracterizam por assentamentos de baixa renda, irregulares e consolidados ou áreas sub-aproveitadas. A finalidade da demarcação destas áreas no território municipal é de promover a recuperação urbanística, a regularização fundiária, o remanejamento e a produção de habitações de interesse social, incluindo a recuperação de imóveis degradados e a provisão de equipamentos sociais e culturais.

A prefeitura de São Luís não tem realizado uma política efetiva de inclusão dos mais pobres à cidade, existem ações de remanejamento de famílias e de regularização fundiária por parte da administração municipal como afirma a Prefeitura de São Luís, através da Secretaria Municipal de Urbanismo e Habitação (SEMURH), mas esse número é ínfimo se comparado a grande demanda. 
Figura 1 - Mapa de zoneamento de 1992 de São Luís atualizado.

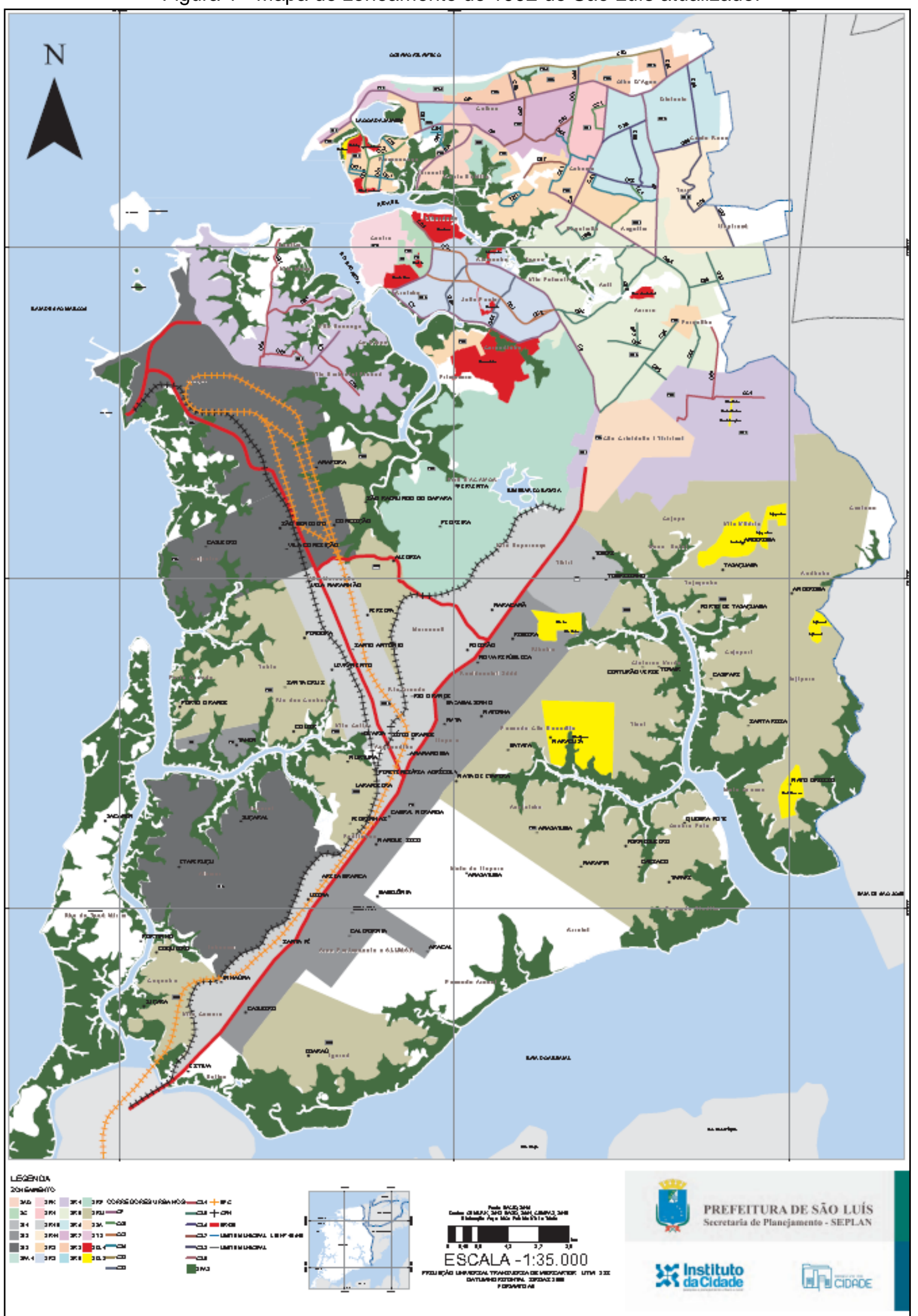

Fonte - SÃO LUÍS (1992); INCID (2018). 
A prefeitura de São Luís não tem realizado uma política efetiva de inclusão dos mais pobres à cidade, existem ações de remanejamento de famílias e de regularização fundiária por parte da administração municipal como afirma a Prefeitura de São Luís, através da Secretaria Municipal de Urbanismo e Habitação (SEMURH), mas esse número é ínfimo se comparado a grande demanda.

As ações da gestão municipal se limitam também a destinar habitações populares, via programas federais, em lugares distantes, na zona rural ou na periferia urbana, o que configura um processo de valorização do espaço capitaneado pelo Estado à serviço das grandes corporações imobiliárias. É perceptível que a legislação não contempla claramente o que se conhece por 'ZEIS de Vazios', que são aquelas que possuem "características redistributivas, pois implicam a alteração dos padrões urbanísticos de modo a destinar para a habitação de interesse social áreas antes retidas para valorização futura, ou destinadas à ocupação por grupos de renda média e alta" (GONDIM e GOMES, 2012, p. 514). É sabido que a utilização das 'ZEIS de vazios' nos planos diretores no Brasil, implantadas depois do Estatuto da Cidade, tem sido pouquíssimo utilizadas, impedindo o acesso por parte de grupos segregados à habitação de interesse popular.

O mapa da Figura 2 mostra áreas de Aglomerados Subnormais na parte norte do município, área mais urbanizada. Estes aglomerados são um conjunto de moradias com um "mínimo de 51 domicílios, ocupando ou tendo ocupado, até período recente, terreno de propriedade alheia (pública ou particular), dispostos, em geral, de forma desordenada e densa" (IBGE, 2010, p. 18), carentes, em sua maioria, de serviços públicos essenciais.

Em 2000 foram catalogadas oito áreas deste tipo na cidade, em 2010 aumentou para vinte e três o número, quase o triplo no intervalo de dez anos. Aliado a isto, a população no município de São Luís saltou de 870.028 em 2000, para 1.014.837 em 2010 e (IBGE, 2010).

As áreas em vermelho no mapa carecem de serviços básicos de qualidade, como coleta de lixo, saneamento básico, pavimentação e iluminação de vias, transporte público, dentre outros. A área do Itaqui-Bacanga (parte sudoeste e oeste do mapa da figura 2), onde há maior quantidade de aglomerados subnormais, por exemplo, concentra uma população em torno de quase 300 mil pessoas em mais de 60 bairros (IBGE, 2010), bairros estes que não estão delimitados em nenhuma ZIS. 


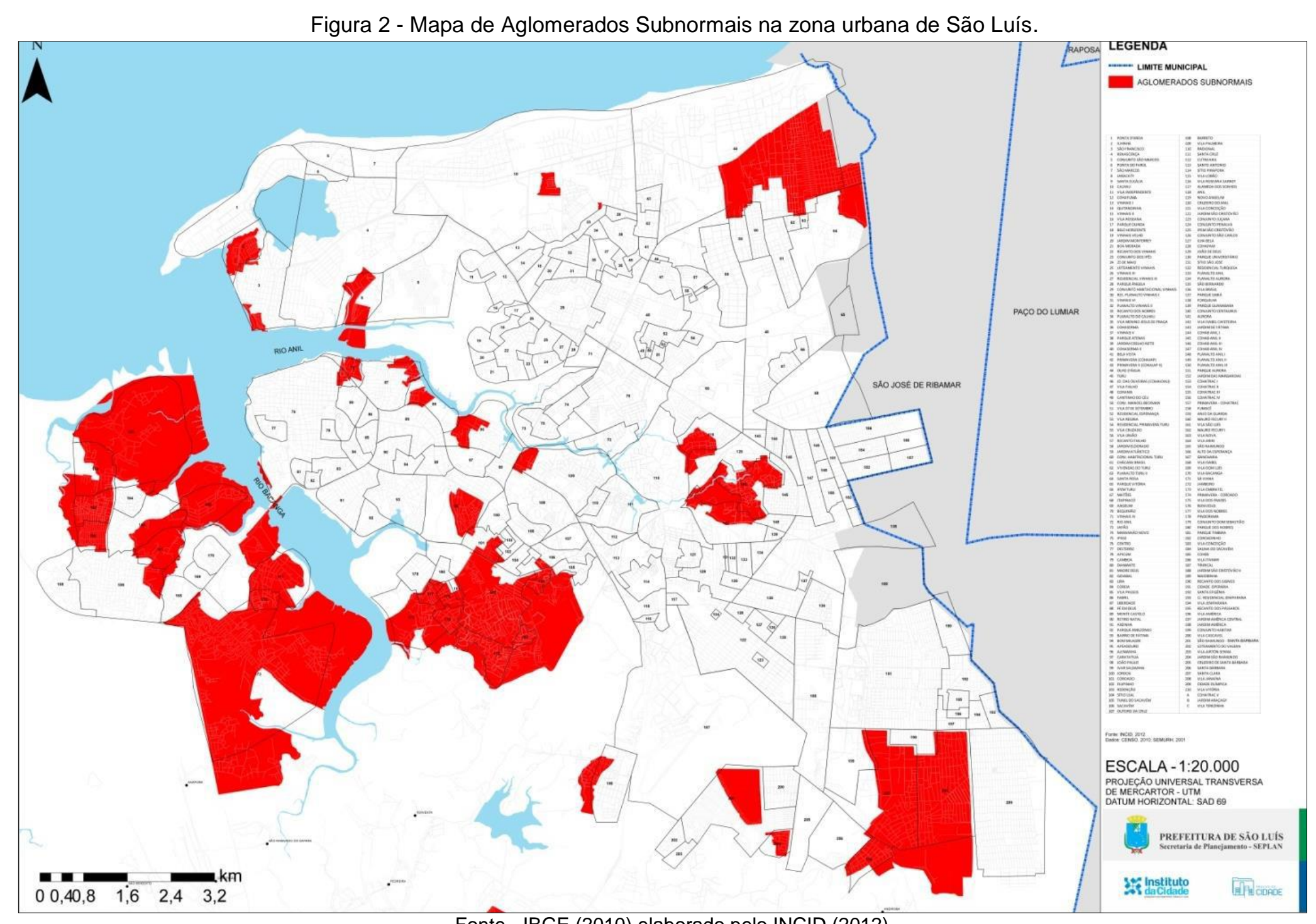

Fonte - IBGE (2010) elaborado pelo INCID (2012). 
O gráfico da figura 3 mostra a questão do esgotamento sanitário em 3 bairros da área Itaqui-Bacanga. A rede geral de esgoto não cobre nem $10 \%$ do total nos três bairros, sendo mais grave a situação no Jambeiro. As fossas sépticas e rudimentares são a principal forma de esgotamento sanitário dos bairros. O poder público municipal, quando age, institucionaliza a segregação socioespacial ao destinar e regularizar áreas com pouca infraestrutura aos grupos mais empobrecidos da sociedade. Se entendida apenas como mera obtenção da garantia de posse da terra, a regularização fundiária está longe de ser suficiente para assegurar o direito à habitação e à cidade.

Figura 3 - Esgotamento sanitário em 3 bairros da área Itaqui-Bacanga

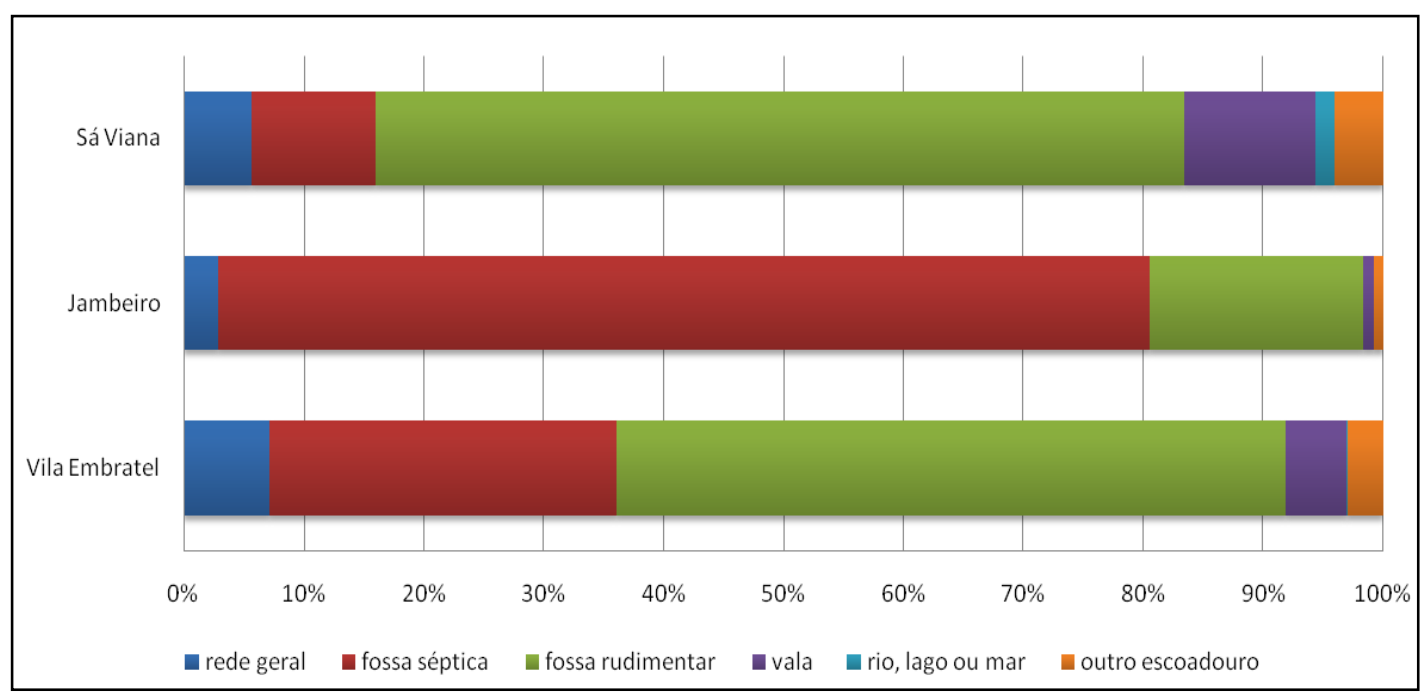

Fonte - IBGE (2010), elaborado pelo autor.

Maricato (2000, p. 177) afirma que "o zoneamento tem contribuído para restringir o mercado e, portanto, o acesso à moradia, por meio de padrões segregadores ou distinguidores". A legislação urbanística auxilia na produção de rendas do solo, que, nada mais são que "ganhos extraordinários localizados, produzidos por um processo de valorização do capital, onde uma parte das condições dessa valorização não podem se reproduzir e são monopolizáveis" (TOPALOV, 1979, p. 135, tradução nossa).

Marcuse (2004, p. 24), afirma que "a segregação é o processo pelo qual um grupo populacional é forçado, involuntariamente, a se aglomerar em uma área definida, em um gueto. É o processo de formação e manutenção de um gueto". Para ele, o Estado é determinante no ato de segregar, ou seja, ele é o responsável por garantir os direitos da propriedade privada contra ocupações, por exemplo. É responsável também por, ao menos na teoria, levar infraestrutura quando da formação de ocupações em áreas urbanas, sejam elas quais forem. Sendo assim, é claro, no âmbito dos poderes mais abrangentes do "Estado a permissão ou a proibição da segregação. Assim, se em qualquer sociedade houver segregação ela ocorrerá com a sanção tácita, quando não explícita, por parte do Estado" (MARCUSE, 2004, p. 30). Este processo, muito comum nos grandes centros urbanos brasileiros, é observado nas políticas públicas urbanas, que reforçam padrões de distinção espacial com a permissão/omissão do Estado. Este por sua vez, reafirma sua vocação para o controle social, originando uma estratégia de funcionalização do espaço.

Desde os anos 1980, que os preços dos imóveis e terrenos nas cidades brasileiras e em São Luís não são apenas determinados pela relação oferta/demanda, mas também pelo planejamento urbano, através das legislações. Desta forma, construída sob uma lógica econômica de mercado, que favorecem incorporadores e "promotores de investimentos imobiliários para os setores de maior renda, a legislação urbana serve basicamente para definir e lhes reservar as melhores áreas, impedindo sua 'invasão' pelos pobres" (ROLNIK, 2015, p. 186). 
Figura 4 - Habitações em aglomerado subnormal, bairro Ilhinha, São Luís.

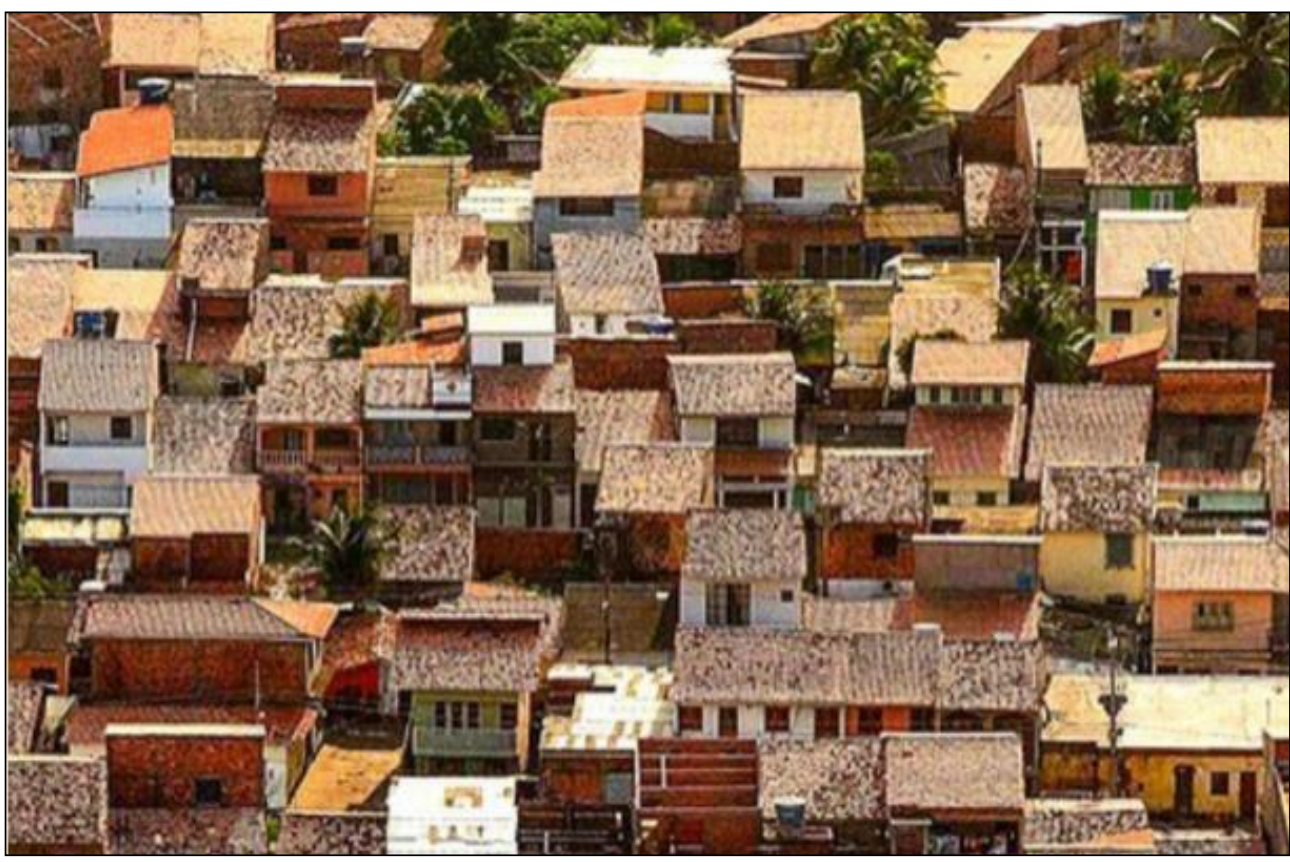

Fonte - Acervo pessoal de Meireles Junior, 2015.

Dito isto, o Estado é um ator essencial no processo de interferência no urbano, por isso cria estratégias que têm por meta a realização do valor, já que orienta os investimentos na construção de infraestrutura, viabilizando a reprodução do capital, instaurando a "ordem urbana, que contém e dissimula uma desordem fundamental, pois a alienação urbana envolve e perpetua todas as alienações. Nela, por ela, a segregação generaliza-se: por classe, bairro, profissão, idade, etnia, sexo" (LEFEBVRE, 2008, p. 87).

O planejamento urbano em São Luís, representado pela legislação urbanística de zoneamento, não tem garantido o acesso da população mais pobre à serviços de qualidade, ao contrário, ela reforça o processo de segregação socioespacial. Longe de ter acesso a itens básicos da vida urbana, o habitante empobrecido de São Luís, que representa mais da metade do total da população, não encontra perspectiva alguma de participar dos processos decisórios da cidade, nem mesmo de participar dos processos culturais e de lazer no espaço intraurbano, um entrave explícito ao direito à cidade. O poder público exclui essa população de uma participação ativa nos processos decisórios locais, eliminando possibilidades de oferecer educação, cultura, lazer e esporte a essa gente, que se encontra à margem da cidade legal.

\section{CONSIDERAÇÕES FINAIS}

O Plano Diretor (PD) e a Lei de Zoneamento constituem o principal marco legal-territorial do município de São Luís. Foi constatado que uma legislação caduca e vigente sobre usos e índices urbanísticos contribui seriamente para o aprofundamento de desigualdades socioespaciais e permite com que os agentes do capital imobiliário se apropriem do destino da cidade a partir de sua íntima relação com o poder público e do conhecimento que possuem sobre essa lei e suas brechas.

Como resultado ainda, foi analisado que pós-2006 houve um incremento na legislação de zoneamento de 1992 - sem qualquer debate público com os habitantes - de diversas Zonas Especiais de Interesse Social (ZEIS), que na lei são chamadas de Zonas de Interesse Social (ZIS). Foi constatada que a grande maioria das comunidades periféricas, situadas ou não em ZIS, não possuem a regularização fundiária, uma população aproximada de pouco mais de meio milhão de pessoas segundo dados do IBGE (2010).

O padrão de produção do espaço em São Luís, bem como de outras grandes aglomerações urbanas no Brasil, se destaca pela presença marcante em sua paisagem, de dois conjuntos de territórios distintos, o primeiro, povoado pelos grupos dominantes, com condomínios verticais e horizontais, que gozam de infraestrutura e serviços diversificados e abundantes. O segundo, apropriado pelos grupos

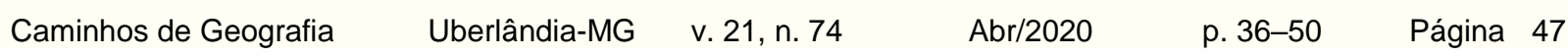


dominados, pobres e espoliados das periferias, que sobrevivem em condições precárias, que sofrem e convivem com a violência e o tráfico e residem em habitações improvisadas, quase sem acesso a itens básicos, como água potável, por exemplo.

A legislação urbanística de zoneamento de 1992 (ainda vigente!) em São Luís foi realizada em gabinete por um grupo seleto de arquitetos, urbanistas e membros do poder político. É enganoso supor que essas leis foram escritas sem o consentimento das incorporadoras e construtoras, já que houve uma inédita ruptura nos padrões construtivos da cidade, permitindo o aumento da quantidade de pavimentos nas construções, representado por edifícios nos bairros nobres da capital maranhense. Além disso, houve uma inoperância quanto às ZIS e às suas populações, gerando uma expansão horizontal acelerada em direção ao município vizinho de São José de Ribamar.

O planejamento urbano em São Luís, representado pelo zoneamento, tem se mostrado a favor de grupos mais abastados, que são beneficiados com maior infraestrutura urbana. Espaços que servem também para a especulação imobiliária, inserção de escritórios, salas comerciais, edifícios para moradias, dentre outros. Em contrapartida, milhares de habitantes vivem em territórios precários, àqueles em que o Estado não se faz presente como deveria, onde os índices de violência imperam e os equipamentos urbanos são exíguos.

\section{AGRADECIMENTOS}

Agradecemos o apoio da Fundação de Amparo à Pesquisa e ao Desenvolvimento Tecnológico do Maranhão - FAPEMA, que tem nos auxiliado com uma bolsa de pesquisa no doutorado em Geografia, ainda em andamento, na Universidade Federal do Ceará.

\section{REFERÊNCIAS}

ALMADA, J. Planejamento e Desenvolvimento do Maranhão: contexto histórico, obstáculos e estratégias de superação. São Luís: Engenho, 2017. 164p. (Coleção Biblioteca Básica Maranhense Volume 1).

AMARAL, J R. O Maranhão Histórico. 2. ed. São Luís: Instituto Géia, 2003. 121p.

ASSELIN, V. Grilagem: corrupção e violência em terras do Carajás. 2. ed. Imperatriz, MA: Ética, 2009. 176p.

BURNETT, F. L. Da tragédia urbana à farsa do urbanismo reformista: a fetichização dos planos diretores participativos. São Paulo: Annablume, 2011. 310p.

São Luís por um Triz: escritos urbanos e regionais. São Luís: EdUEMA, 2012.

CARVALHO, H. F. Urbanização em São Luís: entre o institucional e o repressivo. 2005. 177f. Dissertação (Mestrado em Ciências Sociais), Universidade Federal do Maranhão, UFMA, São Luís, 2005.

CARVALHO, A. P. S. Estatuto da Cidade e jurisdição da reforma urbana no Brasil. Rio de Janeiro: Contra Capa, 2016. 240p.

FERREIRA, A. J. A. Dinâmica de ocupação espacial-uso do solo em São Luís no período de 1950 a 2000. Cadernos de Pesquisa (UFMA), São Luís, v. 13, n. 2, p. 25-36, 2002.

GEBARA, A. O mercado de trabalho livre no Brasil. São Paulo: Brasiliense, 1986. 221p.

GOMES, J. T. P. Síntese Histórica da Formação Urbana de São Luís. Revista FIPES, São Luís, v. 3, n. 2, p. 17-25, jul/dez, 1988.

GONDIM, L. M. P; GOMES, M. P. A. O Direito à cidade em disputa: o caso da Zeis do Lagamar (Fortaleza-CE). Cadernos Metropóle. São Paulo, v. 14, n. 28, p. 507-527, 2012.

GRAZIA, G. Reforma urbana e Estatuto da Cidade. In: RIBEIRO, L. C. Q; CARDOSO, A. L. Reforma Urbana e Gestão Democrática: promessas e desafios do Estatuto da Cidade. 2. ed. Rio de Janeiro: Revan/FASE, 2012. P. 53-70.

HARVEY, D. O direito à cidade. Lutas Sociais. São Paulo, n. 29, p. 73-89, jul./dez. 2012.

O Novo Imperialismo. 7. ed. São Paulo: Edições Loyola, 2013. 201p.

$\begin{array}{llllll}\text { Caminhos de Geografia } & \text { Uberlândia-MG } & \text { v. 21, n. } 74 & \text { Abr/2020 } & \text { p. 36-50 } & \text { Página } 48\end{array}$


Cidades Rebeldes: do direito à cidade à revolução urbana. São Paulo: Martins Fontes selo Martins, 2014. 294p.

INSTITUTO BRASILEIRO DE GEOGRAFIA E ESTATÍSTICA (IBGE). Censos Demográficos 1960, 1970, 1980, 1991, 2000, 2010. Disponível em: <http://www.censo2010.ibge.gov.br>. Acesso em 10. set. 2019.

Aglomerados Subnormais do Censo 2010. Disponível em: http://www.censo2010.ibge.gov.br/agsn/. Acesso em 10 set. 2018.

LACROIX, M. L. L. A fundação francesa de São Luís e seus mitos. 3. ed. São Luís: Editora UEMA, 2008. 184p.

LEFEBVRE, H. A vida cotidiana no mundo moderno. São Paulo: Ática, 1991. 215p.

$O$ direito à cidade. São Paulo: Centauro Editora, 2001. 144p.

A Revolução Urbana. Belo Horizonte: Editora da UFMG, 2008. 176p.

LOPES, J. A. V. (Org.). São Luís, Ilha do Maranhão e Alcântara: Guia de Arquitetura e Paisagem. São Luís-Sevilla, 2008. 444p.

São Luís, capital moderna e cidade colonial: Antônio Lopes da Cunha e a Preservação do Patrimônio Cultural Ludovicense. São Luís: Editora Aquarela/Fundação Municipal de Cultura, 2013. 328p.

MARANHÃO, Companhia de Habitação do Estado. Problema Habitacional do Maranhão. São Luís. 1976.

MARANHÃO. Plano Diretor de São Luís. São Luís, Secretaria de Planejamento, Sioge, 1977.

MARCUSE, P. Enclaves, sim; Guetos, não: a segregação e o Estado. Espaço e Debates. São Paulo, NERU, v. 24, n. 45, p. 24-33, jan./jul, 2004.

MARICATO, E. As ideias fora do lugar e o lugar fora das ideias: planejamento urbano no Brasil. In: ARANTES, Otília et. al. (orgs.). A cidade do pensamento único: desmanchando consensos. 3. ed. Petrópolis: Vozes, 2000. p. 121-192.

. Brasil, Cidades: alternativas para a crise urbana. Petrópolis: Vozes, 2001. 208p.

MEIRELES, M. M. História do Maranhão. São Paulo: Siciliano, 2002. 392p.

História de São Luís. São Luís: Edições AML, 2015. 259p.

RIBEIRO, L. C. Q. Metamorfoses da Ordem Urbana da Metrópole Brasileira: o caso do Rio de Janeiro. Sociologias (UFRGS), v. 18, p. 120-160, 2016. https://doi.org/10.1590/15174522-018004205

RIBEIRO, L. C. Q.; CARDOSO, A. L. Plano Diretor e gestão democrática da cidade. In:

(Orgs.) Reforma Urbana e Gestão Democrática: promessas e desafios do Estatuto da Cidade. 2. ed. Rio de Janeiro: Revan/FASE, 2012. p.103-118.

RIBEIRO JUNIOR, J. R. B. Formação do Espaço Urbano de São Luís: 1612-1991. São Luís: Ed. do Autor/FUNC, 2001. 150p.

ROLNIK, R. Guerra dos Lugares: a colonização da terra e da moradia na era das finanças. São Paulo: Boitempo, 2015. 423p.

SANTOS, L. E. N. Do Areal ao Monte Castelo. O Estado do Maranhão, Opinião, São Luís, p. 4-4, 17. jun. 2009a.

O espaço geográfico e a expansão urbana: implicações no município de São Luís-MA (1950-2000). 2009. 63p. (Especialização em Geoprocessamento Aplicado ao Cadastro Multifinalitário). Centro de Desenvolvimento de Conhecimentos e Habilidades (CEDECON), São Luís, 2009b.

A Grande Artéria. O Estado do Maranhão, Opinião, São Luís, p. 4-4, 31. mar. 2010.

SANTOS, M. Por uma Geografia Nova: da crítica da Geografia à uma Geografia Crítica. 6. ed. São Paulo: EDUSP, 2012 (Coleção Milton Santos 2). 285p. 
$170 p$.

Da Totalidade ao Lugar. São Paulo: Edusp, 2005, p. 21 - 41. (Coleção Milton Santos 7).

SÃO LUíS. Lei 2.527 de 30 de julho de 1981. Dispõe sobre o zoneamento, parcelamento, uso e ocupação do solo urbano de São Luís e dá outras providências. São Luís, 1981.

Lei 3.252 de 29 de dezembro de 1992. Dispõe sobre a instituição do Plano Diretor do município de São Luís, e dá outras providências. São Luís, 1992.

Lei 3.253 de 29 de dezembro de 1992. Dispõe sobre o Zoneamento, Parcelamento, Uso e Ocupação do Solo Urbano e dá outras providências. São Luís, 1992.

VILLAÇA, F. Uma contribuição para a história do planejamento urbano no Brasil. In: DEÁK, Csaba; SCHIFFER, Sueli Ramos (Orgs.). O processo de urbanização no Brasil. 2. ed. São Paulo: EDUSP, 2010. p.169-243.

TOPALOV, C.. La Urbanización Capitalista: algunos elementos para su análisis. México: Edicol, 1979. 137p

Recebido em: 21/03/2019

Aceito para publicação em: 20/03/2020 